\section{Universidades}

\section{Universidades}

ISSN: 0041-8935

udual1@servidor.unam.mx

Unión de Universidades de América Latina y el Caribe

Organismo Internacional

Woldenberg, José

Democracia y participación

Universidades, núm. 34, mayo-agosto, 2007, pp. 41-46

Unión de Universidades de América Latina y el Caribe

Distrito Federal, Organismo Internacional

Disponible en: http://www.redalyc.org/articulo.oa?id=37303405

- Cómo citar el artículo

- Número completo

- Más información del artículo

- Página de la revista en redalyc.org

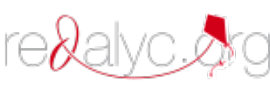

Sistema de Información Científica

Red de Revistas Científicas de América Latina, el Caribe, España y Portugal

Proyecto académico sin fines de lucro, desarrollado bajo la iniciativa de acceso abierto 


\title{
DEMOCRACIA Y PARTICIPACIÓN
}

\author{
José Woldenberg*
}

\section{La transición democrática}

A lo largo de un poco más de veinte años México se vio involucrado en una espiral constructiva en el terreno político. Sus principales fuerzas y las corrientes más profundas, si bien desataron conflictos y desencuentros sin fin, fueron capaces de concurrir a un esfuerzo mayúsculo: el de edificar un escenario legal e institucional para que la diversidad política pudiese expresarse, competir y convivir de manera pacífica.

Fue una etapa cargada de tensiones que se convirtieron en el acicate para abrir el espacio institucional a la pluralidad, de innovaciones constitucionales y legales recurrentes con el fin de aclimatar el debate y la contienda entre contrarios, de creaciones institucionales para ofrecer garantías a la diversidad, de fenómenos inéditos que modificaron radicalmente el mundo de la representación política. En una palabra, se trató de un tránsito democratizador que se convirtió, primero, en el horizonte de las principales fuerzas políticas y luego en una realidad, explotada y vivida por todos.

El reclamo democratizador de 1968 y la respuesta represiva con la que * Profesor titular de tiempo completo de la Facultad de Ciencias Políticas y Sociales de la UNAM; director de la revista Nexos, México. una conflictividad creciente en muy diversos campos (universidades, sindicatos, organizaciones agrarias y populares y la irrupción de una guerrilla urbana y otra campesina), lo que demandaba reformas capaces de ofrecerle un cauce institucional a esa diversidad de expresiones que no se reconocían ni deseaban hacerlo en un sistema político vertical y prácticamente monocolor.

La reforma de 1977 reconoció esa realidad y mediante la apertura del sistema hacia las corrientes políticas a las que se mantenía artificialmente marginadas e inyectándole pluralidad a la Cámara de Diputados abrió las puertas al cambio. Construyó así un cauce para empezar a transformar el autoritarismo en democracia. Durante los primeros años, la diversidad ideológica empezó a tomar cartas de naturalización, la convivencia entre adversarios se extendió, aparecieron y se fortalecieron los brotes de auténtica competencia. En fin, no sin agudos conflictos, el horizonte parecía claro: o espacio para todos o desgaste interminable. se pretendió aplastarlo, fue seguido de 
La fase más intensa de ese proceso transformador se vivió entre 1988 -unas elecciones realmente competidas bajo un marco legal e institucional que no permitió el juego limpio- y la reforma de 1996. En esos años que se vivieron al borde del precipicio, gobiernos y oposiciones fueron capaces de construir instituciones y procedimientos que garantizaran la imparcialidad, condiciones de la competencia medianamente equitativas, conductos para dirimir los diferendos con altos grados de certeza, fórmulas para integrar los cuerpos legislativos, puertas de entrada y salida para nuevas ofertas políticas, y un diseño democrático para el gobierno del Distrito Federal.

Vista de manera panorámica se trató de una espiral constructiva (por supuesto no exenta de episodios ominosos) que logró sintonizar el mundo de las instituciones políticas a la pluralidad que recorría y recorre a la nación. Ello fue posible porque los principales actores comprendieron que sólo el formato democrático ofrecía las condiciones para su convivencia pacífica y su competencia política, $y$ porque fueron capaces de impulsar y diseñar las reformas necesarias.

Quien hoy compare el mundo de la representación política con lo que sucedía hace veinte años encontrará evidencias de sobra. Presidentes municipales de partidos distintos conviviendo con gobernadores diversos; fenómenos de alternancia en todos los niveles dependiendo de los humores públicos; congresos plurales, muchos de ellos sin mayorías absolutas; inexistencia de ganadores y perdedores predeterminados; presidencia de la república acotada por una densa pluralidad instalada en el Congreso y los gobiernos estatales, etcétera. En fin, la diversidad política implantada en la sociedad encontró un espacio institucional para su recreación y coexistencia. A esa etapa algunos le llamamos de transición democrática. Y se trató de una espiral vir- tuosa que permitió sintonizar al mundo de la política institucional con el país real.

Pero la democracia no es una estación terminal. Menos un imposible espacio idílico. La democracia porta sus propios problemas, su agenda está cargada de nuevos retos, y precisamente la colonización del espacio estatal por una pluralidad viva y con arraigo plantea con su sola existencia dificultades antes impensables (y por supuesto impensadas).

\section{El Informe del PNUD}

El 21 de abril en Perú fue presentado el "Informe sobre el desarrollo de la democracia en América Latina 2004", elaborado por el Programa de las Naciones Unidas para el Desarrollo (PNUD). Se trata de un esfuerzo realizado por un equipo de especialistas que intenta medirle el pulso a las democracias realmente existentes en nuestro continente y detectar y reflexionar sobre sus retos. La información abarca 18 naciones y México no resulta un caso excepcional, sino todo lo contrario, porta retos similares al del conjunto de la región.

La democracia en América Latina se ha expandido con velocidad en los últimos tiempos. "Hace veinticinco años, de los dieciocho países incluidos en el Informe, sólo Colombia, Costa Rica y Venezuela eran democráticos". Hoy, sin embargo, el Informe considera que todo el universo de países estudiados (Argentina, Bolivia, Brasil, Chile, Colombia, Costa Rica, Ecuador, El Salvador, Guatemala, Honduras, México, Nicaragua, Panamá, Paraguay, Perú, República Dominicana, Uruguay y Venezuela) lo es. Esa constatación puede ser el piso para evaluar el vigor de la aspiración y el movimiento democrático, pero también un buen punto de partida para acercarse a sus debilidades. 
Porque como bien afirma Dante Caputo, director del Informe, "no hay malestar con la democracia, pero hay malestar en la democracia". Y ese malestar por supuesto es expresión de la forma en que la democracia se reproduce y de los "frutos" escasos que en materia de mejoramiento de las condiciones materiales de vida acompañan a su expansión.

En la presentación, Caputo subraya que "existe el peligro en el ejercicio de explorar lo que falta, olvidar lo que tenemos", es decir, que al llamar la atención sobre los problemas, las lagunas, las asechanzas que gravitan sobre la democracia, olvidemos el significado profundo de haber dejado atrás "la larga noche del autoritarismo", "la historia de los miedos, los asesinatos, las desapariciones, las torturas y el silencio aplastante de la falta de libertad. La historia donde unos pocos se apropiaron del derecho de interpretar y decidir el destino de todos".

Uno de los hilos conductores centrales del trabajo lo constituye la idea de que la fortaleza de la democracia dependerá de la fortaleza de la ciudadanía, entendida como la capacidad real de los ciudadanos para ejercer el conjunto de sus derechos (políticos, civiles y sociales). Porque la paradoja mayor de nuestro continente parece ser la de una ciudadanía construida a medias, que ha logrado ejercer un buen número de derechos políticos pero carente de la posibilidad de apropiación real de los derechos cívicos y sociales. La idea, al parecer recogida de los estudios de Guillermo O'Donell, resulta pertinente porque de la extensión y la calidad en el ejercicio de la ciudadanía dependerá la calidad y las fórmulas de reproducción o erosión de la democracia.

Las coordenadas dentro de las cuales se reproduce la vida en común en el continente latinoamericano son complejas, cargadas de tensiones y singularidades. Se trata de tres dimensiones que se conjugan: democracia, pobreza y desigualdad.
Mientras nuestros índices de participación electoral se encuentran entre los de Estados Unidos (por debajo de la media latinoamericana) y los de Europa (por encima), el porcentaje de pobres es abrumadoramente superior entre nosotros ( $42.2 \%$ contra $15 \%$ en Europa y $11.7 \%$ en Estados Unidos) y una monumental desigualdad cruza por todos los países. O para decirlo en palabras del Informe: "Por primera vez en la historia, una región en desarrollo y con sociedades profundamente desiguales está, en su totalidad, organizada políticamente bajo regímenes democráticos. Así se define en América Latina, una nueva realidad sin antecedentes: el triángulo de la democracia, la pobreza y la desigualdad",

En 2001 la región contaba con 209 millones de habitantes, cuyos ingresos los situaban por debajo de la línea de la pobreza y a esa desgracia en sí misma, debemos sumar el agravante de ser el continente con la mayor desigualdad en el mundo (la distribución del ingreso en América Latina es más desigual que África, aunque la zona no es más pobre). Ese penoso triángulo construye democracias pobres y desiguales, y sobre todo ciudadanos inconclusos, ya que a la vez

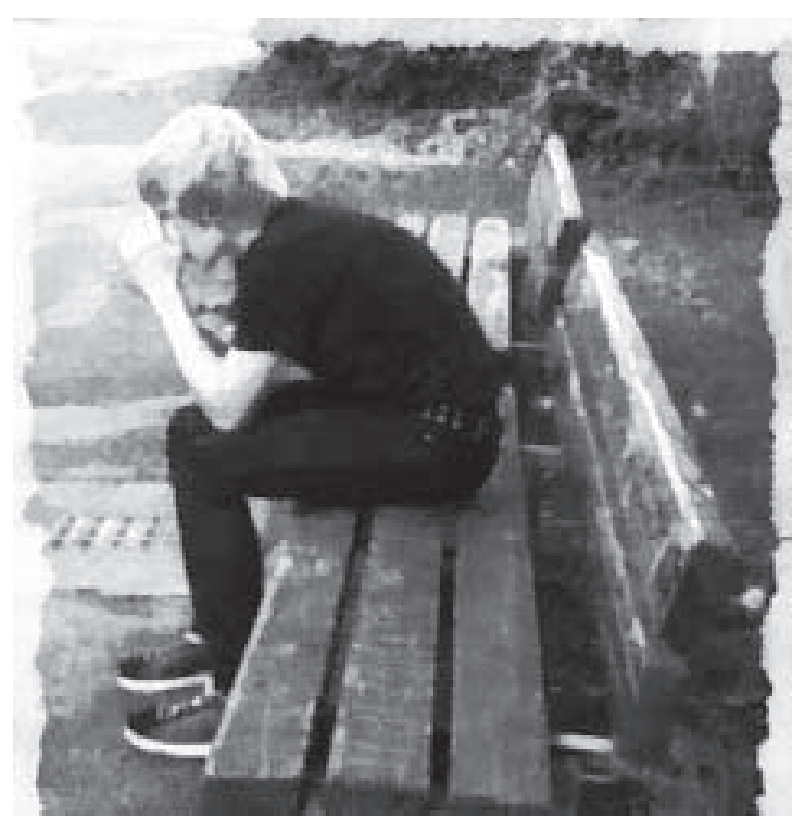


que deben fortalecer y consolidar sus derechos políticos tienen que completar y acceder a los derechos civiles y sociales.

Tenemos pues ciudadanos incompletos, que ejercen sus derechos con baja intensidad y muchos de ellos incluso se encuentran excluidos del ejercicio de derechos básicos. Porque mientras en todos los países se reconoce el derecho universal al voto, se eligen a las autoridades, los fenómenos de alternancia se vuelven recurrentes y la discriminación persiste, las fuertes desigualdades ante la justicia se reproducen todos los días (derechos civiles), la pobreza se extiende y segrega y el trabajo informal se multiplica y erosiona la inclusión social (derechos sociales).

Esa situación no sólo genera escasa cohesión y conflictos múltiples, sino un malestar y desafecto hacia la política, que puede ser el caldo de cultivo para reacciones contrarias a la democracia. De tal suerte, que como dice el Informe, no está de más preguntarnos cómo tiñen a nuestra política esos fenómenos y ¿cuánta pobreza y cuánta desigualdad toleran las democracias? Porque como señala Mark Malloch Brown (administrador del PNUD), si bien la democracia se ha extendido en América Latina no debemos olvidar que "sus raíces no son profundas".

En la encuesta que se aplicó como parte de los instrumentos del Informe se "muestra una tensión entre la opción por el desarrollo económico y la democracia", ya que buena parte de los latinoamericanos valoran al primero por encima de la segunda. Tampoco resulta casual que "en los países con menores niveles de desigualdad los ciudadanos tiendan a apoyar más la democracia". Es decir, el papel corrosivo que la pobreza y la desigualdad pueden tener para la convivencia democrática emerge con fuerza del Informe del PNUD. Y por ello, resultaría suicida darles la espalda.
En suma, todo parece indicar que por primera vez en la historia como continente estamos obligados a resolver los problemas de la pobreza y la desigualdad en democracia, como requisito para fortalecer a ésta última y hacerla sustentable.

\section{Participación ciudadana y cultura política democrática}

Creo que podemos convenir en la idea de que el buen funcionamiento del régimen democrático precisa replantear a la política como el eje ordenador de la actividad del Estado y de forma obligada pasa por la formación de ciudadanos capaces de asumir un papel activo en la sociedad. Dicho de otro modo, en democracia la política tiene que ser una actividad eminentemente ciudadana y no una responsabilidad exclusiva y excluyente de una minoría que se asume como "representante del pueblo", es decir, es menester que el ciudadano se reconozca como tal: como el sujeto de la política y no como el objeto pasivo de los actos de gobierno.

En ese punto tenemos un déficit que no conviene subestimar. Datos de encuestas sobre cultura ciudadana y educación cívica realizadas respectivamente por el IFE y la Secretaría de Gobernación para México, revelan que hay serios problemas en la visión que los ciudadanos tienen acerca de los valores, las instituciones y la legalidad democrática. Prevalece en muchos sentidos una idea autoritaria o intolerante de las relaciones sociales, así como bajísimos niveles de información política. Se valora como atributo principal en un gobernante que sea un "líder fuerte" por encima de otro que conozca y aplique siempre las leyes. Una buena parte de los ciudadanos encuestados no lee la prensa y no atiende a las noticias que se refieren a la política en radio y televisión, pero juzga sumariamente con calificaciones negativas al Congreso, los partidos 
y la policía. La dimensión de lo público aparece en general como un universo ajeno y poco confiable.

Esos datos parecen estar en concordancia con lo que nos indica el Informe del PNUD. Son todavía muchos los ciudadanos en nuestros países que "están de acuerdo con que el presidente vaya más allá de las leyes" (58.1\%), que "creen que el desarrollo económico es más importante que la democracia" (56.3\%), que "apoyarían a un gobierno autoritario si resuelve problemas económicos (54.7\%), que "no creen que la democracia solucione los problemas el país" (43.9\%), que "creen que puede haber democracia sin partidos" (40.0\%), "que puede haber democracia sin un Congreso" (38.2\%).

Hay, pues, una suerte de antagonismo entre la participación electoral efectiva de esos ciudadanos probados en las elecciones y sus nociones básicas acerca de la democracia que a muchos nos parece paradójica o, por lo menos, digna de atención y de ninguna manera irrelevante.

La presencia de esos rasgos en la cultura política de América Latina nos demuestran que el cambio político no produce modificaciones lineales ni unívocas en la percepción de la vida pública, que no hay nada automático en la formación de una conciencia favorable a las instituciones y los sujetos de la democracia y que, por lo mismo, se hace necesario un esfuerzo suplementario por parte de los partidos, los medios, los gobiernos, los organismos no gubernamentales, sobre todo en el ámbito escolar, que ayuden a elevar y fortalecer los valores democráticos.

Especialmente en la escuela. Porque no será en el ámbito familiar, ni a través de los medios masivos de comunicación, y mucho menos por la inercia social, como lograremos que los jóvenes hagan suyos los valores que dan sentido y justificación a la democracia. Es en el espacio escolar donde (creo) hay que redoblar los esfuerzos para contribuir a la forja de un ciudadano capaz de asumir y hacer respetar sus derechos, pero al mismo tiempo comprender sus obligaciones.

Es posible que en los países de larga tradición democrática la participación ciudadana siga las líneas de una costumbre que se reproduce a sí misma, pero en el caso de nuestras democracias sería por completo injustificable asimilar la fragilidad de la cultura democrática a la expresión de una inexistente rutina electoral o al imposible desencanto del modelo representativo.

Justo por la razón de que nuestra zona es heterogénea, diversa y subdesarrollada, donde aún coexisten o se combinan las formas modernas de organización política con la tradición de la democracia comunitaria y la herencia autoritaria, es indispensable no cejar en el empeño de elevar el nivel de la cultura cívica propiamente democrática de modo que al participar los ciudadanos lo hagan informados y, por decirlo así, libremente, con pleno conocimiento de causa.

Por supuesto, la disposición ciudadana a participar está correlacionada positivamente con la valoración de la propia actividad política, pues a mayor descrédito de la política, entre más sea concebida como una actividad inherentemente corrupta, mezquina y carente de sentido, más fino es el suelo sobre el que puede echar raíces el sistema democrático.

Desde esa perspectiva, la responsabilidad no puede ni es exclusiva de la escuela. Políticos y medios de comunicación son, a querer o no, corresponsables.

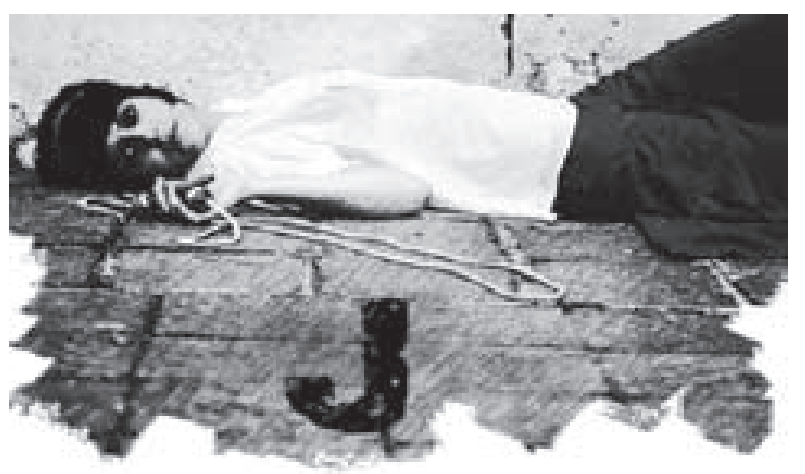




\section{La responsabilidad de los políticos}

Nuestra consolidación democrática no avanzará, no podrá hacerlo, si no es por obra y disposición de los propios políticos y sus partidos. En una democracia son ellos, como representantes legítimos de la sociedad, quienes deben adoptar el papel de vanguardia y poner en juego las visiones de Estado y de país por las que finalmente los ciudadanos decidirán optar. Pero no hay construcción que merezca o pueda ser emprendida sin diagnósticos, sin proyectos, sin propuestas serias y rigurosas acerca del país, sus problemas y sus oportunidades. Bien vistas las cosas, la calidad de nuestras democracias se refleja en la calidad de los partidos, de sus políticos, y de sus programas legislativos y de gobierno. Una vida política sin ideas puede generar una democracia vacía y vulnerable; los partidos tienen en sus manos el privilegio y la responsabilidad de aportar en sus propuestas y en sus acciones diarias los sustantivos y los verbos de la democracia.

Y sin embargo, como lo documenta el multicitado Informe del PNUD, el aprecio hacia los políticos, los partidos y el Congreso son sumamente bajos. No se trata, por desgracia, de un asunto circunscrito a uno o dos países, sino que en general el apoyo del que gozan los partidos y el Parlamento es escaso. Preocupantemente escaso.

Insisto, el presente y el futuro de la democracia, y con ellos el de los millones de personas que conforman la sociedad latinoamericana, están en manos de los responsables directos del Estado, de los partidos. Por eso tienen, como pocas otras instituciones, un papel insoslayable.

\section{La responsabilidad de los medios de comunicación}

La cuestión de los medios tiene una dimensión universal y está presente en la deliberación de todas las democracias modernas. Por ello, la preocupación por el papel de los medios en la democracia no es un tema aleatorio o secundario. De hecho, la reflexión sobre la relación entre medios y política es una tarea imprescindible para consolidar los cambios alcanzados y mejorar la calidad de nuestra convivencia democrática, pues no hay política democrática, política de masas, política moderna, que no pase por los medios de comunicación masiva.

$Y$ al leer el Informe uno no puede dejar de detenerse, con preocupación, en los comentarios de los dirigentes que observan en ocasiones con alarma el comportamiento de los medios. Se les considera un "control sin control", "suprapoderes", se afirma que "la clase política les teme". Se trata de voces que subrayan el nuevo protagonismo de los medios, el despliegue de sus potencialidades, y la necesidad de regular su actuación si es que deseamos que contribuyan en el proceso de consolidación democrática.

Está claro que los medios no sustituyen a la escuela en su función de educar y tampoco suplantan a los partidos, pero hay que reconocer que influyen sobre la cultura cívica de la ciudadanía, que finalmente encarna o no los valores de la democracia.

Así como en el terreno estrictamente político el reto radica ahora en consolidar la democracia, en el campo de los medios tenemos por delante el desafío de pasar de garantizar la pluralidad a asegurar la calidad y el profesionalismo informativo.

En suma, la democracia implica y supone la participación ciudadana. Es a través de ella que la primera adquiere sentido cabal. Pero me temo que la participación ciudadana informada y responsable sólo será posible si se desata la concurrencia de la escuela, los medios y los políticos. 